\title{
Amphetamine in Adolescence Disrupts the Development of Medial Prefrontal Cortex Dopamine Connectivity in a dcc-Dependent Manner
}

\author{
Lauren M Reynolds ${ }^{1,2}$, Carolina S Makowski ${ }^{1,2}$, Sandra V Yogendran ${ }^{1,2}$, Silke Kiessling ${ }^{2}$, Nicolas Cermakian ${ }^{2}$ \\ and Cecilia Flores ${ }^{*, 2,3}$
}

IIntegrated Program in Neuroscience, McGill University, Montréal, Québec, Canada; ${ }^{2}$ Douglas Mental Health University Institute, Montréal,

Québec, Canada; ${ }^{3}$ Department of Psychiatry and Department of Neurology and Neurosurgery, McGill University, Montréal, Québec, Canada

\begin{abstract}
Initiation of drug use during adolescence is a strong predictor of both the incidence and severity of addiction throughout the lifetime. Intriguingly, adolescence is a period of dynamic refinement in the organization of neuronal connectivity, in particular medial prefrontal cortex (mPFC) dopamine circuitry. The guidance cue receptor, DCC (deleted in colorectal cancer), is highly expressed by dopamine neurons and orchestrates their innervation to the MPFC during adolescence. Furthermore, we have shown that amphetamine in adolescence regulates DCC expression in dopamine neurons. Drugs in adolescence may therefore induce their enduring behavioral effects via DCC-mediated disruption in mPFC dopamine development. In this study, we investigated the impact of repeated exposure to amphetamine during adolescence on both the development of mPFC dopamine connectivity and on salience attribution to drug context in adulthood. We compare these effects to those induced by adult exposure to an identical amphetamine regimen. Finally, we determine whether DCC signaling within dopamine neurons is necessary for these events. Exposure to amphetamine in adolescence, but not in adulthood, leads to an increase in the span of dopamine innervation to the mPFC, but a reduction of presynaptic sites present on these axons. Amphetamine treatment in adolescence, but not in adulthood, also produces an increase in salience attribution to a previously drug-paired context in adulthood. Remarkably, DCC signaling within dopamine neurons is required for both of these effects. Drugs of abuse in adolescence may therefore induce their detrimental behavioral consequences by disrupting mesocortical dopamine development through alterations in the DCC signaling cascade.

Neuropsychopharmacology (20 I5) 40, I I0 I-I I I2; doi: I0.1038/npp.20I4.287; published online 19 November 20 I4
\end{abstract}

\section{INTRODUCTION}

Initiation of drug use during adolescence is a strong predictor of both the incidence and severity of lifetime drug abuse and addiction (Robins and Przybeck, 1985; Anthony and Petronis, 1995; Grant and Dawson, 2003). This vulnerability is especially troubling considering that the majority of individuals who begin to experiment with drugs of abuse are under the age of 18 years old (Madras, 2010; Currie and Wild, 2012; Leatherdale and Burkhalter, 2012; SAMHSA, 2012; Swendsen et al, 2012). The risk of lifetime addiction appears to be greatest the earlier drug use commences (Grant and Dawson, 2003; McCabe et al, 2007), suggesting that the detrimental effects of drug exposure in adolescence are intimately linked to ongoing neurodevelopmental processes. Adolescence is a period of

\footnotetext{
*Correspondence: Dr C Flores, Douglas Mental Health University Institute, (Perry Pavilion, room\# 21 I I) 6875 LaSalle Blvd., Montréal, Québec H4H IR3, Canada, Tel: +514 76I 6131 ext: 28I4, Fax: +5I4 762 3034, E-mail: cecilia.flores@mcgill.ca

Received 27 June 20।4; revised 4 October 20।4; accepted I5 October 2014; accepted article preview online 22 October 2014
}

dynamic refinement in the organization of neuronal circuitry. In particular, prefrontal cortex connectivity continues to develop until early adulthood, with this brain region being the last to achieve full maturity (Giedd et al, 1999; Sowell et al, 1999, 2003; Gogtay et al, 2004; Shaw et al, 2008). The protracted development of the prefrontal cortex confers an extended period of plasticity and vulnerability for disruption in its wiring patterns.

One of the most dramatic changes occurring in the prefrontal cortex during adolescence is the establishment of dopamine connectivity. In rodents, the dopamine innervation to the medial prefrontal cortex (mPFC) increases progressively beyond the weaning stage until early adulthood, with substantial modifications in fiber density, shape, and organization happening during adolescence (Kalsbeek et al, 1988; Benes et al, 2000; Manitt et al, 2011; Naneix et al, 2012). In parallel to these changes in dopamine circuitry, local mPFC neurons shift towards a mature state of responsiveness to the modulatory effects of dopamine (Spear, 2000; Tseng and O'Donnell, 2007; O'Donnell, 2011; Cass et al, 2013). The delayed maturation of the dopamine inputs to the mPFC is unique within the monoamine systems (Levitt and Moore, 1979; Lidov et al, 1980; Benes et al, 2000) 
and also occurs in primates, possibly including humans (Rosenberg and Lewis, 1995). Drugs of abuse during adolescence may therefore produce their enduring detrimental effects on behavior by disrupting the developmental trajectory of the dopamine innervation to the $\mathrm{MPFC}$.

We recently identified $d c c$ as the first gene shown to orchestrate the development of dopamine connectivity to the mPFC specifically in adolescence (Manitt et al, 2011, 2013). DCC (deleted in colorectal cancer) is a receptor for the guidance cue netrin-1 and is highly and conspicuously expressed by dopamine neurons in rodents and humans throughout the lifetime. DCC expression in dopamine neurons is high during early development and adolescence, in line with the maturational timeline of dopamine pathways. Interestingly, DCC expression is substantially lower during adulthood, suggesting that DCC signaling may play a different, more local, role in the adult brain (Osborne et al, 2005; Grant et al, 2007; Manitt et al, 2010; Reyes et al, 2013; Yetnikoff et al, 2007, 2010, 2011, 2013a). Using rodents, we showed that DCC signaling within the ventral tegmental area (VTA) dopamine neurons determines the extent of their innervation to the $\mathrm{MPFC}$ specifically during adolescence and, in turn, organizes the structure and function of mPFC local circuitries (Manitt et al, 2013). Variations in DCC expression in dopamine neurons during adolescence lead to dramatic changes in mPFC-dependent behaviors in adulthood, including changes in sensitivity to behavioral effects of drugs of abuse (Manitt et al, 2013). Remarkably, we have also demonstrated that repeated exposure to an abused dose of amphetamine during early adolescence downregulates DCC expression in the rodent VTA (Yetnikoff et al, 2011). Together, these findings raise the intriguing possibility that drugs of abuse during adolescence disrupt the development of dopamine connectivity by regulating DCC signaling within dopamine neurons.

Here, we sought to determine whether repeated exposure to an abused dose of amphetamine in early adolescent C57BL/6 mice disrupts the development of mPFC dopamine connectivity. To confirm that the effects of amphetamine exposure in adolescence result from perturbations in dopamine development, we also examine the effects of adult drug exposure on $\mathrm{mPFC}$ dopamine circuitry organization. We used conditional transgenic mouse models to assess whether DCC signaling within dopamine neurons mediates amphetamine-induced disruption in adolescent dopamine development. Finally, we examined behavioral correlates of altered $\mathrm{mPFC}$ dopamine development in adulthood.

\section{MATERIALS AND METHODS}

\section{Animals}

All experiments and procedures were performed in accordance with the guidelines of the Canadian Council of Animal Care and the McGill University/Douglas Mental Health University Institute Animal Care Committee. Mice were bred in the Douglas Mental Health University Institute Neurophenotyping center, maintained on a 12-h light-dark cycle (light on at $0700 \mathrm{~h}$ ) and given ad libitum access to food and water. Pups were weaned at postnatal day (PND) $21 \pm 1$ and housed with same-sex littermates. dcc conditional mice. We have generated a dcc loss-offunction mutation exclusively in dopamine neurons by crossing mice with loxP-insertions flanking exon 23 of the $d c c$ gene $\left(d c c^{l o x / l o x}\right)$ with a line in which iCre expression is regulated by the dopamine transporter (DAT; BAC-DATiCre

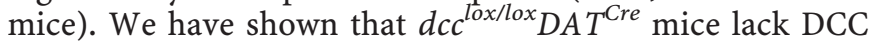
expression exclusively in dopamine neurons and that the absence of DCC expression does not affect DA neuron survival; for a complete description of the characterization of these mice, please refer to Manitt et al (2013). The $d c c^{\text {lox/lox } D A T^{\text {Cre }}}$ mice survive to adulthood and do not exhibit any overt phenotypic differences from control $d c c$-floxed littermates. Floxed, cre-negative littermates $\left(d c c^{l o x / l o x}\right)$ are indistinguishable from wild-type mice, and were utilized in the experiments examining adolescent or adult mice. Different cohorts of floxed controls and

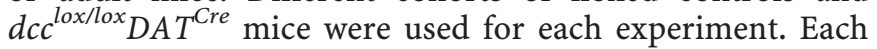
experiment had cohorts from a minimum of 5 litters.

\section{Drugs and Dose}

d-Amphetamine sulfate (AMPH; Sigma-Aldrich, Dorset, United Kingdom) was dissolved in $0.9 \%$ saline. All AMPH injections were administered i.p. at a volume of $0.1 \mathrm{ml} / 10 \mathrm{~g}$. Although there is no clear formula for converting human doses to mice, comparable plasma concentrations of a drug in the two species would be expected to lead to comparable brain concentrations (Kuczenski and Segal, 2005). A dose of $4 \mathrm{mg} / \mathrm{kg}$ of AMPH achieves plasma concentrations $>250 \mathrm{ng} / \mathrm{ml}$ in mice (Riffee et al, 1978; Van Swearingen et al, 2013), which is within the range of plasma levels achieved by oral doses of AMPH that have been reported to be abused by adolescents (Kramer et al, 1967; Anggård et al, 1970; Gustavsen et al, 2006). Importantly, we have shown previously that this dose of AMPH, administered in the same regimen as the present experiments, alters the expression of DCC in the VTA (Yetnikoff et al, 2010, 2011).

\section{Neuroanatomical Analysis}

Perfusion. Mice received an overdose of sodium pentobarbital ( $>75 \mathrm{mg} / \mathrm{kg}$, i.p.) and were perfused intracardially with $50 \mathrm{ml}$ of $0.9 \%$ saline followed by $75 \mathrm{ml}$ of chilled fixative solution (4\% paraformaldehyde in phosphate-buffered saline). Brains were dissected and placed in the fixative solution overnight at $4{ }^{\circ} \mathrm{C}$ and were then transferred to phosphatebuffered saline and stored for a maximum of 2 days. Brains were sectioned using a vibratome (35- $\mu$ m-thick slices).

Immunofluorescence. Every second section was processed for immunofluorescence (1:2 series) as before (Manitt et al, 2010, 2011, 2013). A rabbit polyclonal anti-TH antibody (1:500 dilution, catalog \#AB152; Millipore Bioscience Research Reagents) and an Alexa Fluor 555-conjugated secondary antibody raised in goat (1:500 dilution, $1 \mathrm{~h}$ incubation, Invitrogen) were used.

Diaminobenzidine immunohistochemistry. Every second section was processed for immunohistochemistry (1:2 series) as before (Manitt et al, 2010, 2011, 2013), using the same rabbit polyclonal anti-TH antibody, a goat anti-rabbit biotinylated secondary antibody (1:250 dilution, catalog 
\# BA1000, Vector Labs), and the Vectastain Elite ABC reagent. Staining was visualized by placing sections in nickel-intensified diaminobenzidine for $1 \mathrm{~min}$.

Stereology. TH-positive varicosities were used as the counting unit to obtain a measure of dopamine presynaptic density, as nearly every dopamine varicosity in the mPFC forms a synapse with a dendritic spine or shaft (Séguéla et al, 1988). Varicosities represent sites where neurotransmitter synthesis, packaging, release, and reuptake most often occur (Benes et al, 1996). Furthermore, we and others have shown that the $\mathrm{TH}$ antibody used in these studies labels dopamine axons but rarely labels norepinephrine axons within the regions of interest (Miner et al, 2003; Manitt et al, $2011,2013)$. As in all our previous neuroanatomical studies, we obtained counts only from the right hemisphere because of the lateralization of dopamine systems.

To assess differences in dopamine connectivity following early adolescent AMPH exposure, we performed stereological quantification of the span and density of TH-positive varicosities in the cingulate, prelimbic, and infralimbic subregions of the pregenual mPFC. We performed identical analyses in the nucleus accumbens (NAcc). We also evaluated the number of TH-positive neurons and their size in the VTA and substantia nigra pars compacta $(\mathrm{SNc})$ using stereology in diaminobenzidine-stained tissue. To assess the total volume of $\mathrm{TH}$-positive fiber innervation (in cubic micrometers) we used the Cavalieri method in Stereoinves-

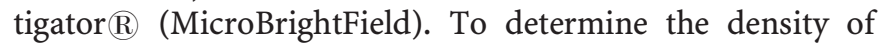
TH-positive varicosities, we used the optical fractionator probe of the Stereoinvestigator software (Manitt et al, 2011, 2013). The coefficient of error was below 0.1 for all regions of interest in all sampled brains. Counts were performed blind.

mPFC analysis. The mPFC subregions were delineated according to plates spanning 14-18 of the mouse brain atlas (Figures 1-3b; (Paxinos and Franklin, 2008)). Contours of the dense TH-positive innervation of the subregions were traced at $\times 5$ magnification using a Leica DM400B microscope (Figure 1c). An unbiased counting frame $(25 \times 25 \mu \mathrm{m})$ was superimposed on each contour and counts were made at regular predetermined intervals $(x=175 \mu \mathrm{m}, y=175 \mu \mathrm{m})$ from a random start point. Counting of varicosities was performed at $\times 100$ magnification on 6 of the 12 sections contained within the rostrocaudal borders of our region of interest (Plates 14-18; 1:2 series). A guard zone of $5 \mu \mathrm{m}$ was used and the optical disector height was set to $10 \mu \mathrm{m}$.

NAcc analysis. An unbiased counting frame $(10 \times 10 \mu \mathrm{m})$ was superimposed on the contour of the NAcc and counts were made at regular predetermined intervals $(x=200 \mu \mathrm{m}$, $y=200 \mu \mathrm{m}$ ) from a random start point. Counting was performed at $\times 100$ magnification on four of the eight sections contained within the rostrocaudal borders of our region of interest (Plates 15-18, 1:2 series; Figure 4a and b; (Paxinos and Franklin, 2008)). A guard zone of $4 \mu \mathrm{m}$ was used and the optical disector height was set to $5 \mu \mathrm{m}$ (Williams et al, 2003).

Number of DA neurons and cell size. The total number of dopamine neurons in the VTA and SNc was assessed using the optical fractionator probe of Stereoinvestigator as previously (Grant et al, 2007; Manitt et al, 2013). The counting scheme used a $60 \times 60 \mu \mathrm{m}$ counting frame $(x=150 \mu \mathrm{m}$, $y=150 \mu \mathrm{m}$ intervals) with a random start point. Counting was performed at $\times 40$ magnification in a 1:4 series. A $3 \mu \mathrm{m}$ guard zone and a probe depth of $10 \mu \mathrm{m}$ were used. The average cell size of TH-positive neurons in the VTA and SNc were estimated using the nucleator function of Stereoinvestigator. Measurements were performed with a $60 \times 60 \mu \mathrm{m}$ counting frame $(x=200 \mu \mathrm{m}, y=200 \mu \mathrm{m}$ intervals $)$ from a random start point. Cell body measurements were performed at $\times 40$ in a 1:8 series (four sections per animal).

\section{Behavioral Evaluation}

Apparatus. Locomotor activity boxes containing infrared sensors (AccuScan Instruments, Columbus, OH, USA) were adapted for use with mice (Yetnikoff et al, 2010, 2013b) by placing inserts that divide the space into four equal parts $(20 \times 20 \times 29.5 \mathrm{~cm}$; Accuscan Instruments). Locomotor activity was defined as distance traveled (centimeters) in a given period of time.

Conditioned locomotor activity. Mice were placed in the previously drug- or saline-paired locomotor chamber and their locomotor activity was recorded for $15 \mathrm{~min}$ in a drugfree state.

\section{Experimental Procedures and Timeline}

Figures 1-3a show the drug treatment regimen used in all the experiments. We have shown that the exact amphetamine regimen, administered in early adolescence, decreases DCC receptor expression in the VTA (Yetnikoff et al, 2011). During a pretreatment phase, mice received one injection of AMPH $(4 \mathrm{mg} / \mathrm{kg}$ ) or vehicle (saline), once every other day for a total of 5 days. This pretreatment regimen was given during early adolescence (from PND $22 \pm 1$ to PND $31 \pm 1$ ) or during adulthood (from PND $75 \pm 15$ to $84 \pm 15$ ). As in our previous work, in this study, we define 'early adolescence' in C57BL/6 mice as the period between the day of weaning and PND 32. These definitions seem now to be a consensus in the mouse literature (eg, (Spear, 2000; Laviola et al, 2003; Schneider, 2013; Tirelli et al, 2003). This is not an absolute margin, but rather an age range during which mice exhibit distinct neurobehavioral characteristics. Locomotor activity was measured $15 \mathrm{~min}$ prior and 90 min after each saline or AMPH injection. Following this pretreatment regimen, mice were left undisturbed for $\sim 6$ weeks to allow adolescent mice to reach adulthood (Figures 1a and 3a). Adult-treated mice were matched to this same interval (Figure 2a). At the end of this interval, mice were brought back to the activity room to assess conditioned locomotor activity. Mice were then perfused and neuroanatomical experiments were performed.

\section{Quantitative Real-Time PCR}

Early adolescent mice received amphetamine from PND $22 \pm 1$ to PND $31 \pm 1$ (Figure 1f). One week after completing this treatment regimen, mice were rapidly decapitated and their brains were flash-frozen in 2-methylbutane (Fisher 


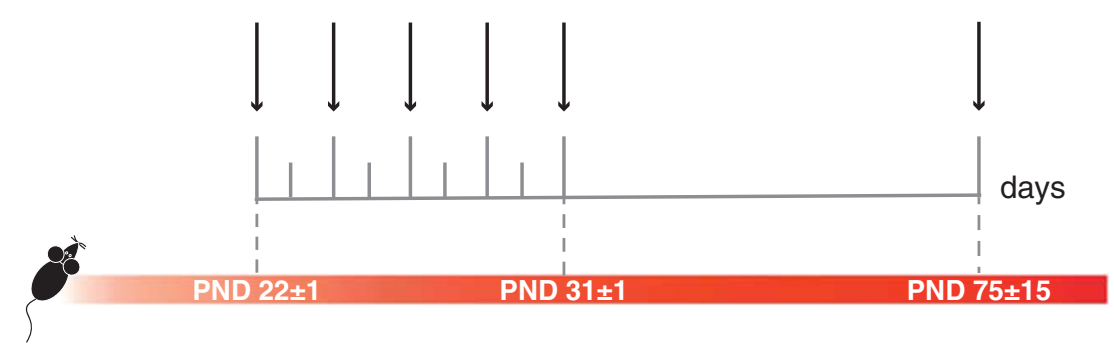

b

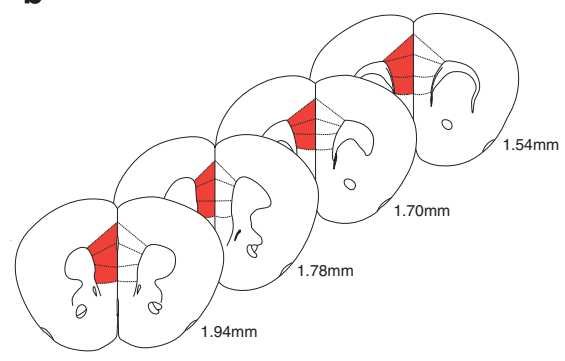

C

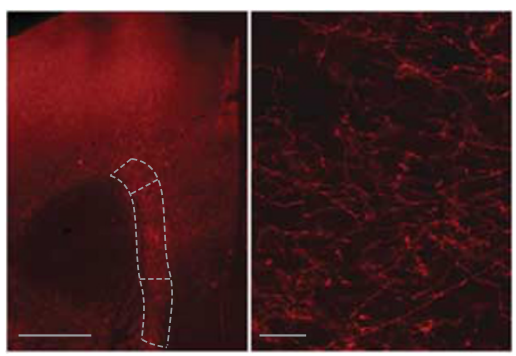

d

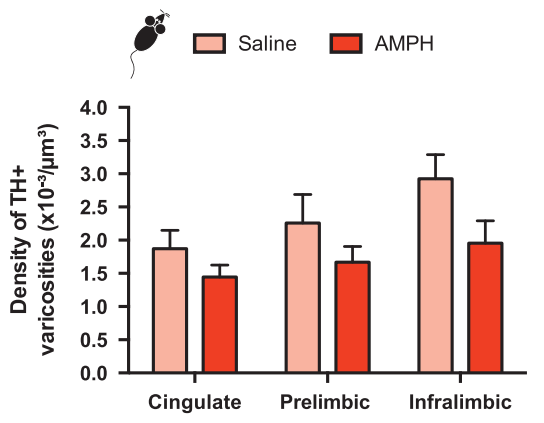

*Main effect of treatment: $F_{(1,30)}=6.655, p=0.01$

${ }^{*}$ Main effect of subregion: $F_{(2,30)}=3.131, p=0.05$

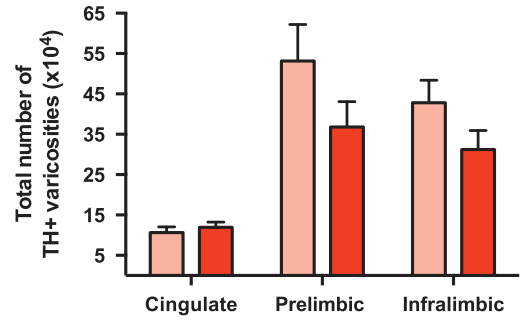

* Main effect of treatment: $F_{(1,27)}=4.871, p=0.03$

*Main effect of subregion: $F_{(2,27)}=18.82, p<0.0001$
*Main effect of subregion: $F_{(2,30)}=50.16, p<0.0001$ f
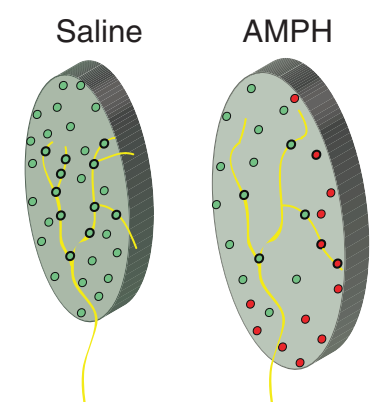

g

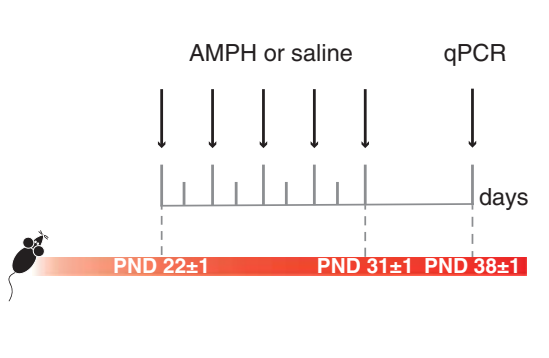

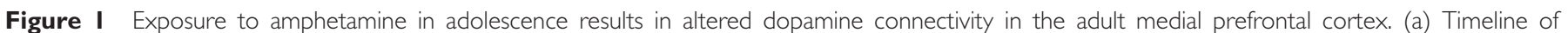

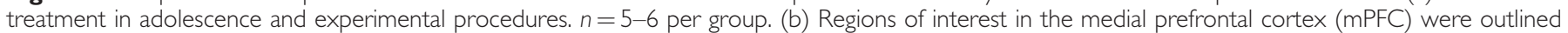

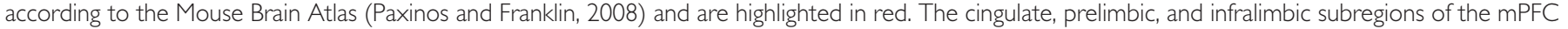

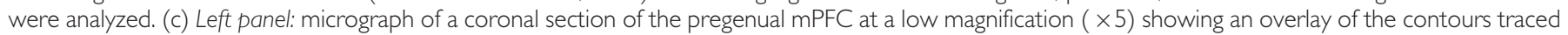

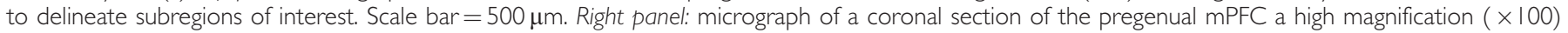

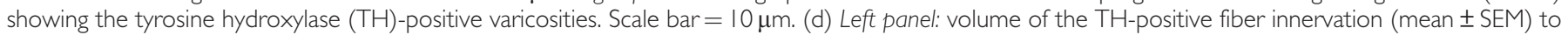

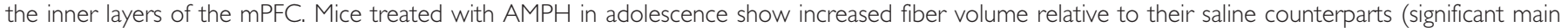

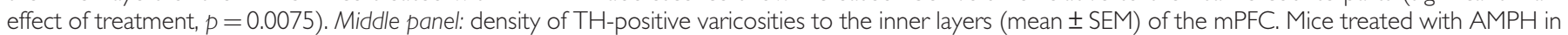

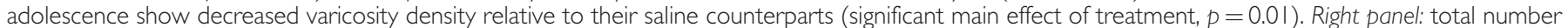

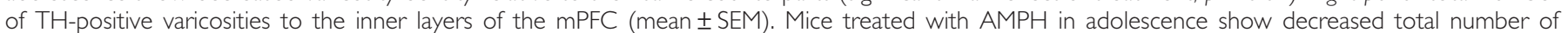

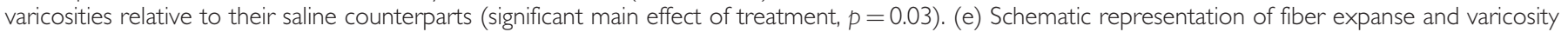

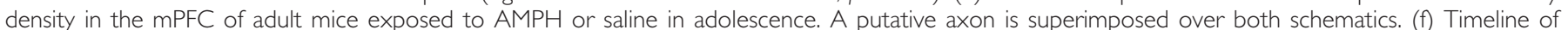

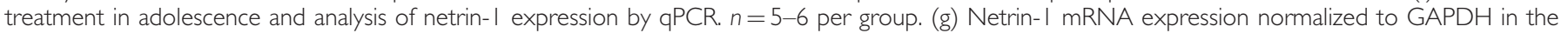

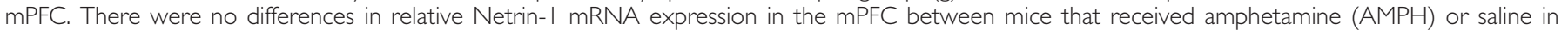
adolescence (from PND22 \pm I - PND3 I \pm I) when examined I week later (PND38 \pm I). 
a

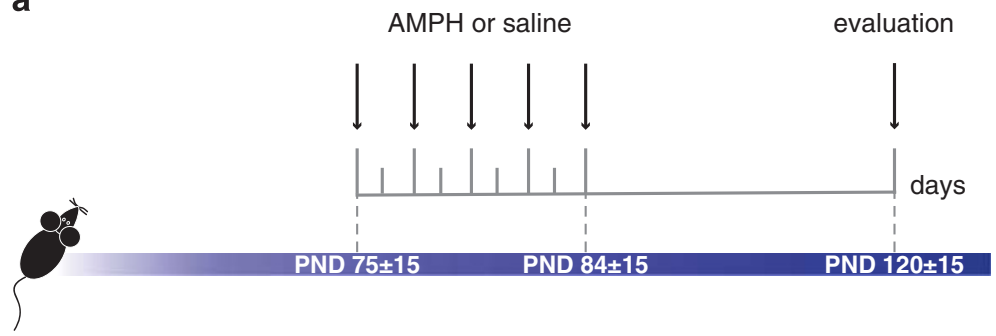

b

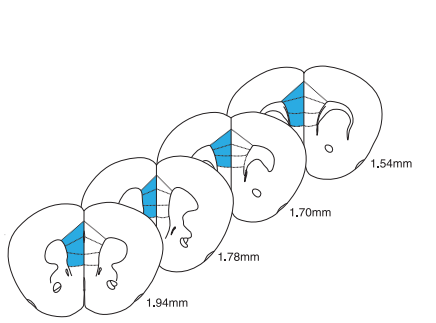

C

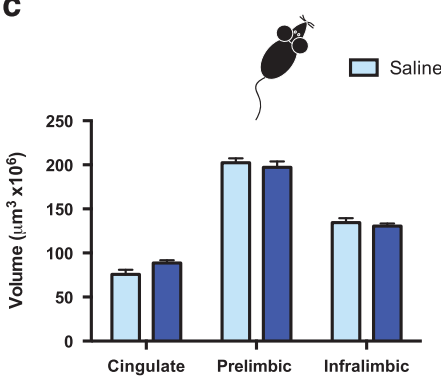

d

Saline AMPH

Figure 2 Exposure to amphetamine during adulthood does not alter dopamine connectivity in the medial prefrontal cortex. (a) Timeline of treatment in adulthood and experimental procedures, $n=8$ per group. (b) Regions of interest in the medial prefrontal cortex (mPFC) were outlined according to the Mouse Brain Atlas (Paxinos and Franklin, 2008) and are highlighted in blue. The cingulate, prelimbic, and infralimbic subregions of the mPFC were analyzed. (c) Left panel: volume of the TH-positive fiber innervation (mean \pm SEM) to the inner layers of the mPFC. There were no differences in the volume of THpositive fiber innervation to the MPFC inner layers between mice that received AMPH or saline in adulthood. Right panel: density of TH-positive varicosities to the inner layers (mean \pm SEM) of the mPFC. The density of TH-positive varicosities to the mPFC inner layers was not different between mice that received AMPH or saline in adulthood. (d) Schematic representation of fiber expanse and varicosity density in the mPFC of adult mice exposed to AMPH or saline in adulthood. A putative axon is superimposed over both schematics.

a

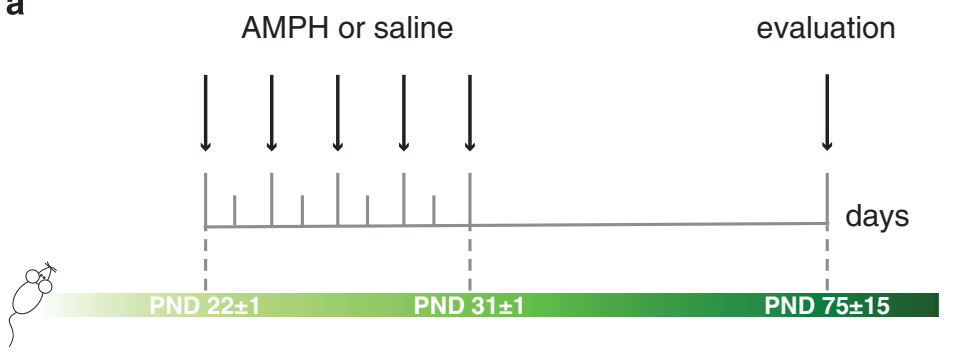

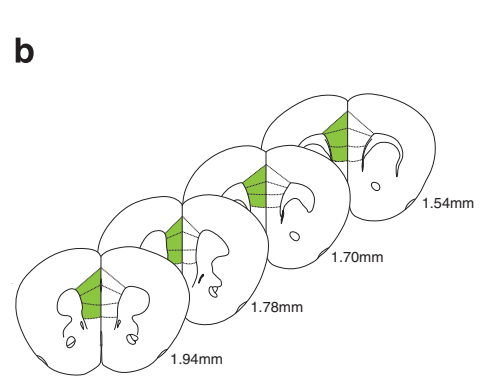

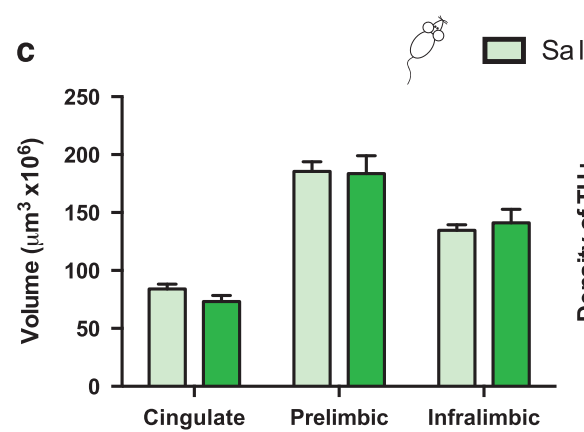

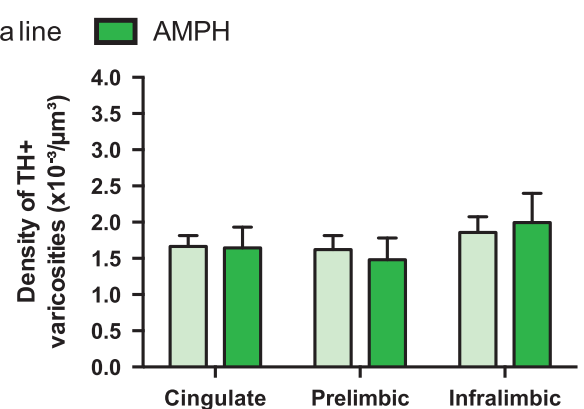

Figure 3 DCC signaling within dopamine neurons is necessary for the effects of amphetamine in adolescence on dopamine connectivity in the medial prefrontal cortex. (a) Timeline of treatment in adolescence and experimental procedures for dcc ${ }^{\text {lox } / 10 x} D A T^{\text {Cre }}$ mice. $n=5-9$ per group. (b) Regions of interest in the medial prefrontal cortex (mPFC) were outlined according to the Mouse Brain Atlas (Paxinos and Franklin, 2008) and are highlighted in green. The cingulate, prelimbic, and infralimbic subregions of the mPFC were analyzed. (c) Left panel: volume of the TH-positive fiber innervation (mean \pm SEM) to the inner layers of the mPFC. There were no differences in the volume of TH-positive fiber innervation to the mPFC inner layers between dcclox/lox DAT ${ }^{\text {Cre }}$ mice that received $\mathrm{AMPH}$ or saline in adolescence. Right panel: density of TH-positive varicosities to the inner layers (mean \pm SEM) of the mPFC. The density of

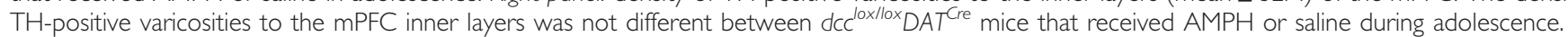

Scientific, Hampton, NH, USA) chilled with dry ice. Bilateral punches of mPFC, including the cingulate (Cg1), prelimbic (PrL), and infralimbic (IL) subregions, were excised from 1-mm-thick coronal sections corresponding to Plates 15-18 (Paxinos and Franklin, 2008). RNA was extracted using Trizol (Life Technologies) according to the manufacturer's 
a

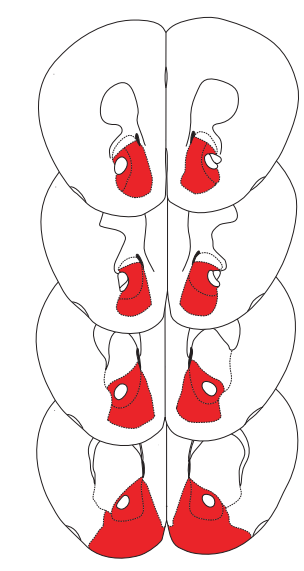

C

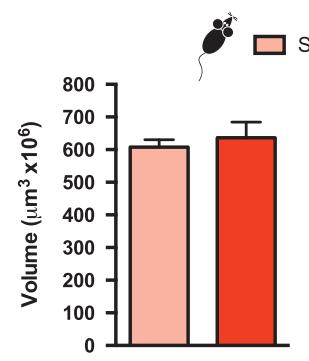

b

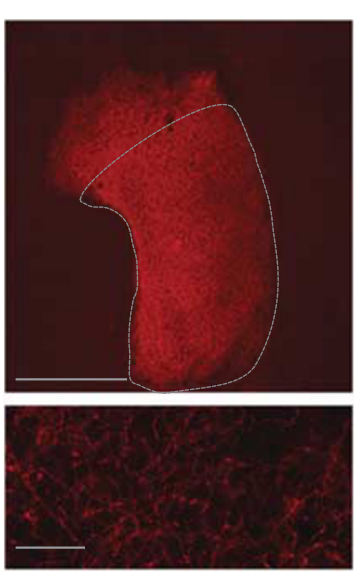

d

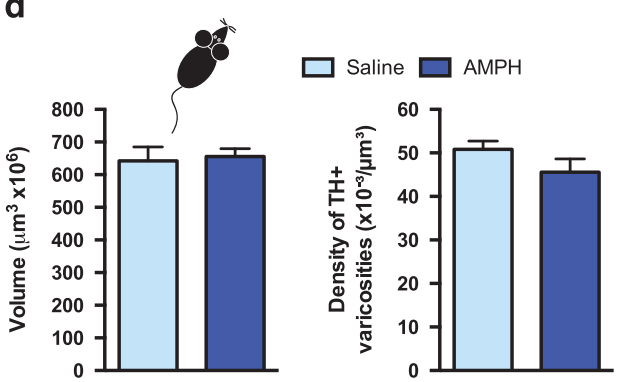

Figure 4 Exposure to amphetamine in adolescence does not result in altered dopamine connectivity in the nucleus accumbens in adulthood. (a) The nucleus accumbens (NAcc) was outlined according to the Mouse Brain Atlas (Paxinos and Franklin, 2008) and highlighted in red. (b) Top panel: micrograph of a coronal section of the pregenual NAcc at a low magnification $(\times 5)$ showing an overlay of the contour traced to delineate this area. Scale bar $=500 \mu \mathrm{m}$. Bottom panel: micrograph of a coronal section of the pregenual NAcc a high magnification $(\times 100)$ showing the tyrosine hydroxylase $(T H)$-positive varicosities. Scale bar $=10 \mu \mathrm{m}$. (c) Left panel: volume of the TH-positive fiber innervation (mean \pm SEM) to the NAcc. There were no differences in the volume of TH-positive fiber innervation to the NAcc between mice that received amphetamine (AMPH) or saline in adolescence (from PND22 \pm IPND3 I \pm I) when examined in adulthood (PND75 \pm I5). Right panel: density of TH-positive varicosities to the NAcc (mean \pm SEM). The density of THpositive varicosities to the NAcc was not different between mice that received AMPH or saline in adolescence. (d) Left panel: volume of the TH-positive fiber innervation (mean \pm SEM) to the NAcc. There were no differences in the volume of TH-positive fiber innervation to the NAcc between mice that received AMPH or saline in adulthood (from PND75 $\pm 15-\mathrm{PND} 84 \pm$ 15) when examined after an approximately 6-week interval following treatment termination (PNDI $20 \pm 15$ ). Right panel: density of TH-positive varicosities to the NAcc (mean \pm SEM). The density of TH-positive varicosities to the NAcc was not different between mice that received $\mathrm{AMPH}$ or saline in adulthood. $n=4-5$ for all groups.

protocol. The concentration was determined with an ND1000 NanoDrop spectrophotometer. cDNA was synthesized using the MultiScribe reverse-transcription kit (Life Technologies) according to the manufacturer's instructions. In all mouse tissues, mRNA expression was assessed with quantitative PCR using TaqMan probes (Life Technologies) as outlined by the manufacturer. Netrin-1 gene expression was assessed with probe set Ntn1 (Mm00500896_m1). GAPDH (glyceraldehyde-3-phosphate; Mm99999915_g1) was used as standard and single-well amplification efficiency estimates and relative quantification of expression levels were performed as described (Pfaffl, 2001).

\section{Statistical Analysis}

The goal of this study was to determine the long-term effects of AMPH exposure on dopamine connectivity. Thus, we planned comparisons between data obtained from $\mathrm{AMPH}$ and saline treatment groups within each exposure age only (either adolescence or adulthood).

Neuroanatomy. Two-way ANOVAs with subregion $\times$ treatment as between-subjects variables were used to analyze the volume of TH-positive fibers and density of TH-positive varicosities in the mPFC for each exposure age group. The effects of $d c c$ on the development of dopamine connectivity in the MPFC vary along the dorso-ventral axis (Manitt et al, 2011, 2013); thus here, as in our previous studies, we include subregion as one of the main factors in the analysis. To analyze TH-positive fiber volume and density of TH-positive varicosities in the NAcc, we used Student's $t$-tests of planned comparisons within each exposure age group. Two-way ANOVAs with region and treatment as between-subjects variables were used to analyze the number and cell size of DA neurons in the VTA and SNc for each exposure age group.

Conditioned locomotor activity. Student's $t$-tests of planned comparisons within each exposure age group were conducted.

Quantitative real-time PCR. Netrin-1 mRNA expression was compared between adolescent saline- or amphetaminetreated mice by Mann-Whitney rank sum test even if 
normality tests and equal variance tests were positive, reflecting the small sample sizes (5-6).

\section{RESULTS}

\section{AMPH in Adolescence, but not in Adulthood, Alters Dopamine Innervation in the $\mathrm{mPFC}$}

The span of TH-positive fiber innervation (in cubic micrometers) in the mPFC of adult mice that received AMPH during adolescence was significantly increased in comparison with mice that received saline during adolescence. Although this effect was distributed across the three subregions, the difference appeared to be more pronounced ventrally (Figure 1d, left panel: two-way ANOVA, main effect of treatment, $\mathrm{F}_{(1,30)}=8.216, p=0.0075$; no significant treatment $\times$ subregion interaction, $\mathrm{F}_{(2,30)}=0.33, p=0.71$; main effect of subregion, $\left.\mathrm{F}_{(2,30)}=50.16, \quad p<0.0001\right)$. Importantly, adolescent exposure to AMPH resulted in a concomitant reduction in the density of TH-positive varicosities in the mPFC. Again, this difference was more pronounced in ventral subregions (Figure $1 \mathrm{~d}$, middle panel: two-way ANOVA, main effect of treatment, $\mathrm{F}_{(1,30)}=6.655$, $p=0.01$; no significant treatment $\times \mathrm{mPFC}$ region interaction, $\mathrm{F}_{(2,30)}=0.3923, p=0.67$; main effect of $\mathrm{mPFC}$ region, $\left.\mathrm{F}_{(2,30)}=3.131, p=0.05\right)$. Correspondingly, mice that received AMPH during adolescence had a significant decrease in the total number of TH-positive varicosities; this effect was more evident in the prelimbic and infralimbic subregions (Figure 1d, right panel: two-way ANOVA main effect of treatment, $F_{(1,27)}=4.871, p=0.036$; no significant treatment $\times \mathrm{mPFC}$ region interaction, $\mathrm{F}_{(2,27)}=1.441$, $p=0.25$; main effect of $\mathrm{mPFC}$ region, $\mathrm{F}_{(2,27)}=18.82$, $p<0.0001)$. The vast majority of dopamine varicosities in the mPFC form synapses (Séguéla et al, 1988). Thus, the increase in the expanse of dopamine innervation coupled with reduced density and total number of dopamine varicosities indicates that AMPH in adolescence alters the development of mPFC dopamine axons and decreases their number of presynaptic sites (Figure 1e).

In contrast, exposure to AMPH during adulthood did not alter dopamine connectivity in the mPFC. There were no differences in the volume of TH-positive fibers between saline- and AMPH-treated littermates in any of the mPFC subregions analyzed (Figure $2 c$, left panel: two-way ANOVA, main effect of treatment, $\mathrm{F}_{(1,42)}=0.1705, p=0.68$; no significant treatment $\times \mathrm{mPFC}$ region interaction, $\mathrm{F}_{(2,42)}=1.5, p=0.23$; main effect of mPFC region, $\left.\mathrm{F}_{(2,42)}=282.5, p<0.0001\right)$. Moreover, there were no differences in the density of TH-positive varicosities in these cortical subregions between saline- and AMPH groups (Figure 2c, right panel: two-way ANOVA, main effect of treatment, $\mathrm{F}_{(1,42)}=0.4883, p=0.48$; no significant treatment $\times$ mPFC region interaction, $\mathrm{F}_{(2,42)}=0.0943, p=0.91$; main effect of $\mathrm{mPFC}$ region, $\left.\mathrm{F}_{(2,42)}=11.23, p=0.0001\right)$. These data indicate that the same AMPH regimen that induces profound changes in adult mPFC DA synaptic connectivity when administered during early adolescence does not alter dopamine connectivity within this region when administered during adulthood (Figure 2d). We have previously shown, that in contrast to early adolescence (Yetnikoff et al, 2011), exposure to the exact same regimen of amphetamine upregulates DCC expression in the VTA when given to adult mice and rats (Yetnikoff et al, 2007, 2010). This age-dependent effect is consistent with the idea that DCC signaling within dopamine neurons mediates different events at different developmental times (Flores, 2011).

\section{Role of $d c c$ in AMPH-Induced Disruption of mPFC Dopamine Wiring}

To determine whether DCC signaling in dopamine neurons plays a role in the AMPH-induced disruption of mPFC dopamine wiring we observe in adult mice after adolescent exposure, we examined the effects of an identical treatment

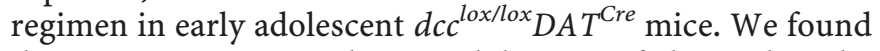
that AMPH exposure during adolescence fails to alter the development of dopamine synaptic connectivity in the $\mathrm{mPFC}$ in mice lacking $d c c$ within dopamine neurons specifically. There were no differences in the volume of TH-positive fibers or density of TH-positive varicosities in the $\mathrm{mPFC}$ between saline- and AMPH-treated

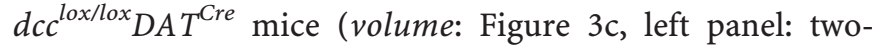
way ANOVA, main effect of treatment, $\mathrm{F}_{(1,48)}=0.07614$, $p=0.78$, main effect of region, $\mathrm{F}_{(2,48)}=66.61, p<0.0001$; density: Figure 3c, right panel: two-way ANOVA, main effect of treatment, $\mathrm{F}_{(1,27)}=0.0014, p=0.96$, main effect of region, $\left.\mathrm{F}_{(2,27)}=1.105, p=0.34\right)$. These findings indicate that DCC signaling within dopamine neurons is required for the effects of AMPH on mPFC DA development (Figure 3d).

\section{Netrin-1 mRNA Expression in the mPFC is not Altered by Adolescent Exposure to AMPH}

Netrin-1, the ligand for the DCC receptor, is highly expressed in the mPFC (Manitt et al, 2011). We used realtime quantitative PCR to determine whether mice exposed to amphetamine in adolescence have altered netrin-1 mRNA expression in the $\mathrm{mPFC}$, which may contribute to the observed disruption of dopamine connectivity. We found that 1 week after the last amphetamine dose, during the period where DCC-mediated netrin-1 signaling is necessary to organize $\mathrm{mPFC}$ dopamine circuitry, netrin-1 mRNA expression did not differ between saline and amphetamine groups (Figure 1g; $U=14, p=0.9$ ). This indicates that adolescent exposure to amphetamine does not alter netrin-1 expression in the mPFC 1 week following drug exposure.

\section{AMPH in Adolescence does not Alter Dopamine Wiring in the NAcc}

Adult mice that received AMPH during early adolescence showed no alterations in the span of TH-positive fibers or in the density of TH-positive varicosities in the NAcc in comparison with their saline counterparts (volume: Figure 4c; left panel: $t_{(6)}=0.54, p=0.61$; density: Figure 4c; right panel: $\left.t_{(6)}=1.423, p=0.20\right)$. Similarly, there were no differences in these two parameters between adult mice that received AMPH during adulthood and their saline counterparts (volume: Figure 4d; left panel: $t_{(8)}=0.2658, p=0.80$; density: Figure $4 \mathrm{~d}$; right panel: $\left.t_{(8)}=1.480, p=0.18\right)$. 
Adolescent Exposure to AMPH does not Alter Soma Size or Number of Dopamine Neurons

To examine the effects of AMPH exposure on dopamine soma size and total numbers, we conducted stereological counts of TH-positive neurons in the VTA and SNc of adult mice treated with AMPH or saline in adolescence. There were no changes in these measurements between drug and saline groups (Dopamine neuron number: VTA, Mean \pm SEM: Saline $=8545 \pm 2046, \mathrm{AMPH}=8832 \pm 1224 ; \mathrm{SNc}$, Mean \pm SEM: Saline $=7519 \pm 1558, \quad$ AMPH $=6689 \pm 1027$ Main effect of treatment, $\mathrm{F}_{(1,8)}=0.03222, p=0.86$. Dopamine neuron size:. VTA, Mean \pm SEM: Saline $=159.28 \pm$ $12.21 \mu \mathrm{m}, \quad \mathrm{AMPH}=152.97 \pm 17.65 \mu \mathrm{m} ; \mathrm{SNc}$, Mean \pm SEM: Saline $=177.43 \pm 16.59 \mu \mathrm{m}, \quad \mathrm{AMPH}=166.21 \pm 21.037 \mu \mathrm{m}$; Main effect of treatment, $\mathrm{F}_{(1,18)}=0.2711, p=0.61$; data not shown).

\section{Augmented Salience Attribution Following Adolescent, but not Adult Exposure to Amphetamine}

We next began to determine whether the effects of AMPH exposure in early adolescence on MPFC dopamine development have consequences on behavioral responses to drug-associated cues in adulthood. Mice were tested, in the absence of drug, for conditioned locomotor activity to their previously drug-paired environment, a behavior which depends on mPFC function (Franklin and Druhan, 2000). Adult mice that were exposed to AMPH during adolescence show significantly greater locomotor activity (95\%) than their saline-treated littermates when re-exposed to the pretreatment environment (Figure 5a: $t_{(8)}=3.71, p=0.006$ ). In contrast, adult mice that received AMPH or saline during adulthood did not show differential locomotor activity when re-exposed to the pretreatment environment (Figure 5b: $\left.t_{(13)}=1.806, p=0.094\right)$. Furthermore, adult $d c c^{\text {lox/lox } D A T^{C r e}}$ mice treated with AMPH or saline during adolescence did not show differences in locomotor activity when re-exposed to the pretreatment environment (Figure $5 \mathrm{c}: t_{(15)}=0.83$, $p=0.42)$. These findings suggest that the DCC-mediated disruption in $\mathrm{mPFC}$ dopamine development induced by
AMPH in adolescence leads to exaggerated contextual salience of drug-related cues in adulthood.

\section{DISCUSSION}

Here, we report that exposure to amphetamine in early adolescence disrupts mPFC dopamine development by altering DCC signaling within dopamine neurons, leading to augmented salience attribution in adulthood. First, we show that mice that receive amphetamine in adolescence, but not in adulthood, have aberrant mPFC dopamine innervation and a stark reduction in dopamine synapses in adulthood. Second, we find that AMPH decreases dopamine presynaptic sites selectively in the mPFC. Third, we show that these developmental effects of amphetamine require DCC signaling within dopamine neurons. Finally, we demonstrate that mice exposed to amphetamine in adolescence, but not in adulthood, show exaggerated contextual salience to previously drug-paired environments; an effect that also depends on DCC signaling within dopamine neurons. These findings support the idea that drugs of abuse in adolescence induce detrimental behavioral consequences by disrupting mesocortical dopamine development. Furthermore, we identify the DCC signaling cascade as a critical mechanistic component of these effects.

\section{DCC-mediated Effects of Amphetamine on the Sculpting of mPFC Dopamine Axons}

Presynaptic sites. In this study, we find that amphetamine administration during adolescence reduces the density of presynaptic sites from dopamine axons specifically in the $\mathrm{mPFC}$. This effect requires DCC signaling within dopamine neurons. DCC-mediated synaptic decrease is in line with the fact that, in addition to their role in axonal guidance, DCC receptors continue to organize neuronal connectivity beyond axonal pathfinding (Dickson, 2002; Chao et al, 2009; Poon et al, 2013). DCC receptors function in a shortrange capacity to dictate axonal target recognition, axon and dendrite arborization, and synaptogenesis (Deiner et al,
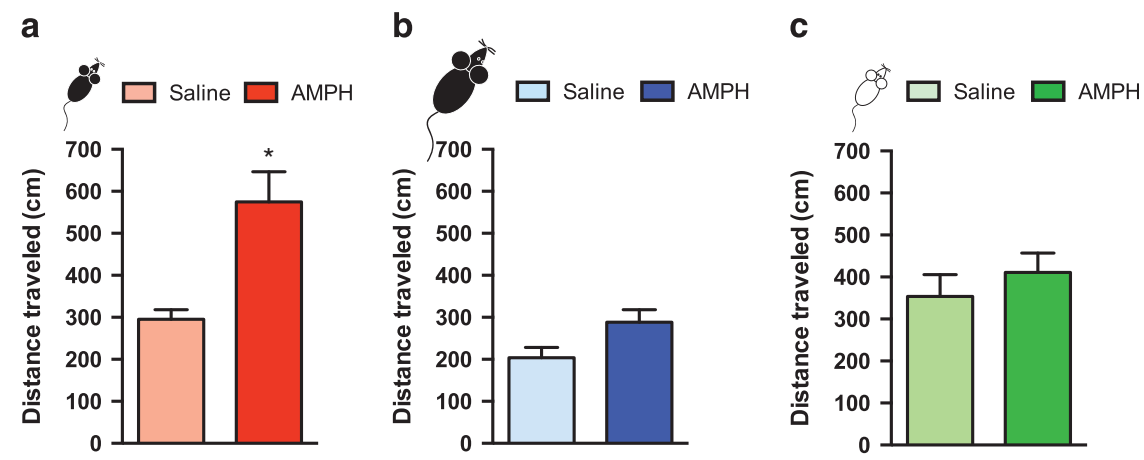

Figure 5 Amphetamine exposure in adolescence, but not in adulthood, leads to augmented salience attribution and requires dcc in dopamine neurons. Salience attribution was quantified by calculating the total locomotor activity across a 15 -min test of conditioned locomotor activity (mean \pm SEM). (a) Mice exposed to amphetamine (AMPH) during adolescence (from PND $22 \pm$ I to PND $31 \pm 1$ ) display augmented salience attribution when re-exposed to the previously drug-paired chamber in adulthood (PND $75 \pm 15$ ), in comparison with their saline controls ( $n=5$ per group; * indicates $p=0.006$ ). (b) Mice exposed to AMPH $(n=7)$ or saline $(n=9)$ during adulthood (from PND $75 \pm 15$ to PND $845 \pm$ I) show no differences in salience attribution when reexposed to a previously drug-paired chamber approximately 6 weeks ( PND I20 \pm I5) after treatment termination. (c) dcc ${ }^{\text {lox/lox }} D A T^{\text {Cre }}$ mice $(n=8$ per group) exposed to AMPH or saline during adolescence (from PND $22 \pm 1$ to PND $31 \pm 1$ ) show no differences in salience attribution when re-exposed to a previously drug-paired chamber in adulthood (PND $75 \pm 15$ ). 
1997; Winberg et al, 1998; Dent et al, 2004; Colón-Ramos et al, 2007; Manitt et al, 2009). Compromised DCC signaling induced by amphetamine during adolescence, a period of intense $\mathrm{mPFC}$ synaptic refinement, may therefore lead to the decrease of dopamine presynaptic sites by disrupting these post-axonal pathfinding events. Blocking DCC function has been shown to dramatically reduce presynaptic sites from retinal ganglion cell axons in a netrin-1dependent manner (Manitt et al, 2009). Netrin-1 is highly expressed by mPFC neurons in layers that are densely innervated by dopamine fibers (Manitt et al, 2011). Therefore, amphetamine in adolescence may 'denude' dopamine axons by limiting the DCC/netrin-1 interaction. Indeed DCC-mediated netrin-1 signaling promotes synaptogenesis in vitro by increasing the probability of axon-dendrite adhesion and, in turn, triggering the formation of presynaptic sites (Goldman et al, 2013). Here, we show that netrin-1 mRNA expression in the mPFC during adolescent synaptic organization is not altered by exposure to amphetamine. Future studies will address whether increasing netrin-1 function in the mPFC would rescue the effects of amphetamine in adolescence on mPFC dopaminergic presynaptic density.

Aberrant innervation. Coupled with the reduction of presynaptic sites, exposure to amphetamine during adolescence induces an increase in the expanse of dopamine fibers to the mPFC. We propose that amphetamine administration, by reducing DCC expression in dopamine neurons (Yetnikoff et al, 2011), leads to the failure of dopamine axons to undergo target recognition processes in noncortical regions, and that these axons instead ectopically innervate the $\mathrm{mPFC}$. Evidence from our group suggests that in adolescence, DCC receptors promote target recognition events by dopamine axons within brain regions that express low levels of netrin-1. When DCC signaling is compromised during this particular developmental period, dopamine axons fail to undergo target recognition events within these regions. Instead, they continue to grow towards the inner layers of the mPFC, where netrin-1 is highly expressed (Manitt et al, 2011). Another possibility is that the increase in the expanse of dopamine innervation results from sprouting of fibers that have already reached the mPFC by adolescence (Kalsbeek et al, 1988; Van den Heuvel and Pasterkamp, 2008). However, blockade of DCC signaling has been shown to reduce axonal branching and differentiation of growing retinal ganglion cells (Manitt et al, 2009).

Because dopamine axons travel through the striatum on their way to cortical targets (Kalsbeek et al, 1988), we hypothesized that amphetamine induces the rerouting of dopamine axons that were destined to innervate the NAcc and/or the dorsal striatum. Dopamine synaptic connectivity undergoes intense dynamic changes in striatal regions during adolescence (Spear, 2000; Antonopoulos et al, 2002; McCutcheon et al, 2012; Naneix et al, 2012). In this experiment, we were not able to identify the differences in dopamine connectivity in the NAcc between adult mice treated with amphetamine or saline during adolescence. However, this apparent lack of effect should be interpreted cautiously. The increase in fiber expanse in the MPFC would correspond to a very small change in dopamine fiber density in striatal regions that may be undetectable by our current anatomical analysis (Manitt et al, 2011). Future studies will explore this idea using conditional viral labeling techniques to investigate detailed dopamine axonal morphology in NAcc and striatal regions.

\section{Behavioral Consequences of Amphetamine-Induced Disruption in mPFC Dopamine Development}

Dopamine axons innervate the mPFC sparsely, but their synaptic connectivity appears to be organized in a very strategic manner (Séguéla et al, 1988). We have shown that small alterations to mPFC dopamine connectivity lead to sizeable changes in the pyramidal neuron morphology and excitability and, consequently, to changes in cognitive processing and responses to drugs of abuse (Grant et al, 2007; Manitt et al, 2011, 2013; Pokinko et al, 2014). Similarly, dopamine function in the human prefrontal cortex has been shown to play a critical role in higherorder cognitive processing, including behavioral inhibition and salience attribution, as well as in the regulation of subcortical reward circuitry (Robbins et al, 1994; Rogers et al, 1999; Tomasi et al, 2007; Goldstein and Volkow, 2011). Thus, by disrupting prefrontal cortex dopamine maturation, drug use in adolescence likely induces deficits in these processes, increasing vulnerability to develop addiction. Indeed, compelling evidence shows prefrontal cortex dysfunction and associated cognitive deficits in stimulant drug abusers (Verdejo-García et al, 2006; Tomasi et al, 2007; Woicik et al, 2011; Ersche et al, 2011; Goldstein and Volkow, 2011; Kohno et al, 2014; ). Furthermore, prefrontal cortex activation in adolescent subjects appears to predict levels of future substance use and dependence symptoms, particularly in individuals who are already high-frequency drug users (Mahmood et al, 2013).

Here, we find that mice exposed to amphetamine in adolescence show exaggerated conditioned locomotor activation when re-exposed to the previously drug-paired environment in adulthood. Conditioned locomotor activity is a measure of contextual salience attribution and depends on mPFC function (Stewart et al, 1984; Cervo and Samanin, 1996; Di Ciano et al, 1998; Franklin and Druhan, 2000; Hall et al, 2008; Robinson and Berridge, 1993, 2008). Whereas the amphetamine regimen used in this experiment produced exaggerated salience attribution when administered in adolescence, it failed to induce salience attribution when administered in adulthood. These findings are the first evidence that drug exposure in adolescence, in comparison with adulthood, renders mice more sensitive to drug-paired cues in adulthood. Remarkably, DCC signaling mediates the effects of amphetamine in adolescence on both dopamine synaptic connectivity and salience attribution, suggesting strongly that these events are causally linked.

The changes in the development of dopamine connectivity induced by amphetamine are more pronounced in the infralimbic cortex subregion. Dopamine input to the mPFC dictates the functional maturation of local circuitry (Manitt et al, 2011, 2013). Thus, our results suggest that aberrant dopamine innervation leads to modifications in infralimbic cortex function. The infralimbic cortex controls cueinduced reinstatement of drug-seeking behavior following extinction (Peters et al, 2008; LaLumiere et al, 2012). In fact, 
this region has been proposed as a key component of the 'stop circuit' substrate mediating the transition from regulated to compulsive drug use (Kalivas, 2008; Peters et al, 2009). We are currently investigating the consequences of disrupted development of dopamine connectivity on the structure and function of infralimbic pyramidal neurons and on behaviors that are linked to infralimbic cortical function.

\section{CONCLUSION}

In this study, we show that a regimen of exposure to an abused dose of amphetamine during adolescence, but not during adulthood, reduces mPFC dopamine connectivity and increases salience attribution of the drug-paired context in adulthood. DCC receptor signaling in dopamine neurons is necessary for both of these effects. Adolescent drug use may therefore influence individual vulnerability to drug addiction through DCC-mediated disruption in the development of mPFC dopamine circuitry, and ultimately, on cognitive function. We have previously shown that variations in DCC, which occur in humans (Srour et al, 2010; Méneret et al, 2014), are associated with psychiatric disorders, including depression and schizophrenia (Grant et al, 2012; Manitt et al, 2013). We propose that factors that confer susceptibility or resilience to psychopathology, including addiction, regulate $D C C$ in adolescence.

\section{FUNDING AND DISCLOSURE}

The authors declare no conflict of interest.

\section{ACKNOWLEDGEMENTS}

This work was funded by the Canadian Institutes of Health Research, Natural Science and Engineering Research Council of Canada, and the Fonds de Recherche du Québec-Santé. LMR is supported by a predoctoral STEM fellowship from Fulbright Canada.

\section{REFERENCES}

Anggård E, Gunne LM, Jönsson L-E, Niklasson F (1970). Pharmacokinetic and clinical studies on amphetamine dependent subjects. Eur J Clin Pharmacol 3: 3-11.

Anthony JC, Petronis KR (1995). Early-onset drug use and risk of later drug problems. Drug and Alcohol Depend 40: 9-15.

Antonopoulos J, Dori I, Dinopoulos A, Chiotelli M, Parnavelas JG (2002). Postnatal development of the dopaminergic system of the striatum in the rat. Neuroscience 110: 245-256.

Benes FM, Taylor JB, Cunningham MC (2000). Convergence and plasticity of monoaminergic systems in the medial prefrontal cortex during the postnatal period: implications for the development of psychopathology. Cereb Cortex 10: 1014-1027.

Benes FM, Vincent SL, Molloy R, Khan Y (1996). Increased interaction of dopamine-immunoreactive varicosities with GABA neurons of rat medial prefrontal cortex occurs during the postweanling period. Synapse 23: 237-245.

Cass DK, Thomases DR, Caballero A, Tseng KY (2013). Developmental disruption of gamma-aminobutyric acid function in the medial prefrontal cortex by noncontingent cocaine exposure during early adolescence. Biol Psychiatry 74: 490-501.
Cervo L, Samanin R (1996). Effects of dopaminergic and glutamatergic receptor antagonists on the establishment and expression of conditioned locomotion to cocaine in rats. Brain Res 731: 31-38.

Chao DL, Ma L, Shen K (2009). Transient cell-cell interactions in neural circuit formation. Nat Rev Neurosci 10: 262-271.

Colón-Ramos DA, Margeta MA, Shen K (2007). Glia promote local synaptogenesis through UNC-6 (netrin) signaling in C. elegans. Science 318: 103-106.

Currie CL, Wild TC (2012). Adolescent use of prescription drugs to get high in Canada. Can J Psychiatry 57: 745-751.

Deiner MS, Kennedy TE, Fazeli A, Serafini T, Tessier-Lavigne M, Sretavan DW (1997). Netrin-1 and DCC mediate axon guidance locally at the optic disc: loss of function leads to optic nerve hypoplasia. Neuron 19: 575-589.

Dent EW, Barnes AM, Tang F, Kalil K (2004). Netrin-1 and semaphorin $3 \mathrm{~A}$ promote or inhibit cortical axon branching, respectively, by reorganization of the cytoskeleton. J Neurosci 24 : 3002-3012.

Di Ciano P, Blaha CD, Phillips AG (1998). The relation between dopamine oxidation currents in the nucleus accumbens and conditioned increases in motor activity in rats following repeated administration of d-amphetamine or cocaine. Eur $J$ Neurosci 10: 1113-1120.

Dickson BJ (2002). Molecular mechanisms of axon guidance. Science 298: 1959-1964.

Ersche KD, Barnes A, Jones PS, Morein-Zamir S, Robbins TW, Bullmore ET (2011). Abnormal structure of frontostriatal brain systems is associated with aspects of impulsivity and compulsivity in cocaine dependence. Brain 134: 2013-2024.

Flores C (2011). Role of netrin-1 in the organization and function of the mesocorticolimbic dopamine system. J Psychiatry Neurosci 36: 296-310.

Franklin TR, Druhan JP (2000). Involvement of the nucleus accumbens and medial prefrontal cortex in the expression of conditioned hyperactivity to a cocaine-associated environment in rats. Neuropsychopharmacology 23: 633-644.

Giedd JN, Blumenthal J, Jeffries NO, Castellanos FX, Liu H, Zijdenbos A et al (1999). Brain development during childhood and adolescence: a longitudinal MRI study. Nat Neurosci 2: 861-863.

Gogtay N, Giedd JN, Lusk L, Hayashi KM, Greenstein D, Vaituzis AC et al (2004). Dynamic mapping of human cortical development during childhood through early adulthood. Proc Natl Acad Sci USA 101: 8174-8179.

Goldman JS, Ashour MA, Magdesian MH, Tritsch NX, Harris SN, Christofi N et al (2013). Netrin-1 Promotes Excitatory Synaptogenesis between Cortical Neurons by Initiating Synapse Assembly. J Neurosci 33: 17278-17289.

Goldstein RZ, Volkow ND (2011). Dysfunction of the prefrontal cortex in addiction: neuroimaging findings and clinical implications. Nat Rev Neurosci 12: 652-669.

Grant A, Fathalli F, Rouleau G, Joober R, Flores C (2012). Association between schizophrenia and genetic variation in DCC: a case-control study. Schizophr Res 137: 26-31.

Grant A, Hoops D, Labelle-Dumais C, Prévost M, Rajabi H, Kolb B et al (2007). Netrin-1 receptor-deficient mice show enhanced mesocortical dopamine transmission and blunted behavioural responses to amphetamine. Eur J Neurosci 26: 3215-3228.

Grant BF, Dawson DA (2003). Age of onset of drug use and its association with DSM-IV drug abuse and dependence: results from the National Longitudinal Alcohol Epidemiologic Survey. J Subst Abuse 10: 163-173.

Gustavsen I, Mørland J, Bramness JG (2006). Impairment related to blood amphetamine and/or methamphetamine concentrations in suspected drugged drivers. Accid Anal Prev 38: 490-495.

Hall DA, Stanis JJ, Marquez Avila H, Gulley JM (2008). A comparison of amphetamine- and methamphetamine-induced 
locomotor activity in rats: evidence for qualitative differences in behavior. Psychopharmacology (Berl) 195: 469-478.

Kalivas PW (2008). Addiction as a pathology in prefrontal cortical regulation of corticostriatal habit circuitry. Neurotox Res 14: 185-189.

Kalsbeek A, Voorn P, Buijs RM, Pool CW, Uylings HB (1988). Development of the dopaminergic innervation in the prefrontal cortex of the rat. J Comp Neurol 269: 58-72.

Kohno M, Morales AM, Ghahremani DG, Hellemann G, London ED (2014). Risky decision making, prefrontal cortex, and mesocorticolimbic functional connectivity in methamphetamine dependence. JAMA Psychiatry 71: 812-820.

Kramer JC, Fischman VS, Littlefield DC (1967). Amphetamine abuse. Pattern and effects of high doses taken intravenously. JAMA 201: 305-309.

Kuczenski R, Segal DS (2005). Stimulant actions in rodents: implications for attention-deficit/hyperactivity disorder treatment and potential substance abuse. Biol Psychiatry 57: 1391-1396.

LaLumiere RT, Smith KC, Kalivas PW (2012). Neural circuit competition in cocaine-seeking: roles of the infralimbic cortex and nucleus accumbens shell. Eur J Neurosci 35: 614-622.

Laviola G, Macrì S, Morley-Fletcher S, Adriani W (2003). Risk-taking behavior in adolescent mice: psychobiological determinants and early epigenetic influence. Neurosci Biobehav Rev 27: 19-31.

Leatherdale ST, Burkhalter R (2012). The substance use profile of Canadian youth: exploring the prevalence of alcohol, drug and tobacco use by gender and grade. Addict Behav 37: 318-322.

Levitt P, Moore RY (1979). Development of the noradrenergic innervation of neocortex. Brain Res 162: 243-259.

Lidov HG, Grzanna R, Molliver ME (1980). The serotonin innervation of the cerebral cortex in the rat-an immunohistochemical analysis. Neuroscience 5: 207-227.

Madras BK (2010). Office of National Drug Control Policy: a scientist in drug policy in Washington, DC. Ann NY Acad Sci 1187: 370-402.

Mahmood OM, Goldenberg D, Thayer R, Migliorini R, Simmons AN, Tapert SF (2013). Adolescents' fMRI activation to a response inhibition task predicts future substance use. Addict Behav 38: 1435-1441.

Manitt C, Eng C, Pokinko M, Ryan RT, Torres-Berrío A, Lopez JP et al (2013). dcc orchestrates the development of the prefrontal cortex during adolescence and is altered in psychiatric patients. Transl Psychiatry 3: e338.

Manitt C, Labelle-Dumais C, Eng C, Grant A, Mimee A, Stroh T et al (2010). Peri-pubertal emergence of UNC-5 homologue expression by dopamine neurons in rodents. PLOS ONE 5: e11463.

Manitt C, Mimee A, Eng C, Pokinko M, Stroh T, Cooper HM et al (2011). The netrin receptor DCC is required in the pubertal organization of mesocortical dopamine circuitry. J Neurosci 31: 8381-8394.

Manitt C, Nikolakopoulou AM, Almario DR, Nguyen SA, CohenCory S (2009). Netrin participates in the development of retinotectal synaptic connectivity by modulating axon arborization and synapse formation in the developing brain. J Neurosci 29: 11065-11077.

McCabe SE, West BT, Morales M, Cranford JA, Boyd CJ (2007). Does early onset of non-medical use of prescription drugs predict subsequent prescription drug abuse and dependence? Results from a national study. Addiction 102: 1920-1930.

McCutcheon JE, Conrad KL, Carr SB, Ford KA, McGehee DS, Marinelli M (2012). Dopamine neurons in the ventral tegmental area fire faster in adolescent rats than in adults. J Neurophysiol 108: $1620-1630$.

Méneret A, Depienne C, Riant F, Trouillard O, Bouteiller D, Cincotta M et al (2014). Congenital mirror movements: Mutational analysis of RAD51 and DCC in 26 cases. Neurology 82: 1999-2002.
Miner LH, Schroeter S, Blakely RD, Sesack SR (2003). Ultrastructural localization of the norepinephrine transporter in superficial and deep layers of the rat prelimbic prefrontal cortex and its spatial relationship to probable dopamine terminals. J Comp Neurol 466: 478-494.

Naneix F, Marchand AR, Di Scala G, Pape J-R, Coutureau E (2012). Parallel maturation of goal-directed behavior and dopaminergic systems during adolescence. J Neurosci 32: 16223-16232.

O'Donnell P (2011). Adolescent onset of cortical disinhibition in schizophrenia: insights from animal models. Schizophr Bull 37: 484-492.

Osborne PB, Halliday GM, Cooper HM, Keast JR (2005). Localization of immunoreactivity for deleted in colorectal cancer (DCC), the receptor for the guidance factor netrin-1, in ventral tier dopamine projection pathways in adult rodents. Neuroscience 131: 671-681.

Paxinos G, Franklin KBJ (2008). The Mouse Brain in Stereotaxic Coordinates. 3rd edn. Amsterdam: Elselvier/Academic Press.

Peters J, Kalivas PW, Quirk GJ (2009). Extinction circuits for fear and addiction overlap in prefrontal cortex. Learn Mem 16: 279-288.

Peters J, LaLumiere RT, Kalivas PW (2008). Infralimbic prefrontal cortex is responsible for inhibiting cocaine seeking in extinguished rats. J Neurosci 28: 6046-6053.

Pfaffl MW (2001). A new mathematical model for relative quantification in real-time RT-PCR. Nucleic Acids Res 29: e45.

Pokinko M, Moquin L, Gratton A, Flores C (2014). Mesocortical dopamine depletion reverses the protective phenotype of netrin1 receptor deficient mice. Program No. 210.07/A51. 2014 Neuroscience Meeting Planner. Society for Neuroscience, 2014. Washington D.C. online.

Poon VY, Choi S, Park M (2013). Growth factors in synaptic function. Front Synaptic Neurosci 5: 6.

Reyes S, Fu Y, Double KL, Cottam V, Thompson LH, Kirik D et al (2013). Trophic factors differentiate dopamine neurons vulnerable to Parkinson's disease. Neurobiol Aging 34: 873-886.

Riffee WH, Ludden TM, Wilcox RE, Gerald MC (1978). Brain and plasma concentrations of amphetamine isomers in mice. J Pharmacol Exp Ther 206: 586-594.

Robbins TW, Roberts AC, Owen AM, Sahakian BJ, Everitt BJ, Wilkinson L et al (1994). Monoaminergic-dependent cognitive functions of the prefrontal cortex in monkey and man Thierry A-M, Glowinski J, Goldman-Rakic PS (eds). Motor and Cognitive Functions of the Prefrontal Cortex. Springer-Verlag: Berlin, Heidelberg, 93-111.

Robins LN, Przybeck TR (1985). Age of onset of drug use as a factor in drug and other disorders. NIDA Res Monogr 56: 178-192.

Robinson TE, Berridge KC (1993). The neural basis of drug craving: an incentive-sensitization theory of addiction. Brain Res Brain Res Rev 18: 247-291.

Robinson TE, Berridge KC (2008). Review. The incentive sensitization theory of addiction: some current issues. Philos Trans $R$ Soc Lond B Biol Sci 363: 3137-3146.

Rogers RD, Everitt BJ, Baldacchino A, Blackshaw AJ, Swainson R, Wynne $\mathrm{K}$ et al (1999). Dissociable deficits in the decisionmaking cognition of chronic amphetamine abusers, opiate abusers, patients with focal damage to prefrontal cortex, and tryptophan-depleted normal volunteers: evidence for monoaminergic mechanisms. Neuropsychopharmacology 20: 322-339.

Rosenberg DR, Lewis DA (1995). Postnatal maturation of the dopaminergic innervation of monkey prefrontal and motor cortices: a tyrosine hydroxylase immunohistochemical analysis. J Comp Neurol 358: 383-400.

SAMHSA (2012). Results from the 2011 National Survey on Drug Use and Health: Summary of national findings. NSDUH Series H-44, HHS Publication No (SMA) 12-4713. Substance Abuse and Mental Health Services Administration: Rockville, MD.

Schneider M (2013). Adolescence as a vulnerable period to alter rodent behavior. Cell Tissue Res 354: 99-106. 
Séguéla P, Watkins KC, Descarries L (1988). Ultrastructural features of dopamine axon terminals in the anteromedial and the suprarhinal cortex of adult rat. Brain Res 442: 11-22.

Shaw P, Kabani NJ, Lerch JP, Eckstrand K, Lenroot R, Gogtay N et al (2008). Neurodevelopmental trajectories of the human cerebral cortex. J Neurosci 28: 3586-3594.

Sowell ER, Peterson BS, Thompson PM, Welcome SE, Henkenius AL, Toga AW (2003). Mapping cortical change across the human life span. Nat Neurosci 6: 309-315.

Sowell ER, Thompson PM, Holmes CJ, Jernigan TL, Toga AW (1999). In vivo evidence for post-adolescent brain maturation in frontal and striatal regions. Nat Neurosci 2: 859-861.

Spear LP (2000). The adolescent brain and age-related behavioral manifestations. Neurosci Biobehav Rev 24: 417-463.

Srour M, Rivière J-B, Pham JMT, Dubé M-P, Girard S, Morin S et al (2010). Mutations in DCC cause congenital mirror movements. Science 328: 592.

Stewart J, de Wit H, Eikelboom R (1984). Role of unconditioned and conditioned drug effects in the self-administration of opiates and stimulants. Psychol Rev 91: 251-268.

Swendsen J, Burstein M, Case B, Conway KP, Dierker L, $\mathrm{He} \mathrm{J}$ et al (2012). Use and abuse of alcohol and illicit drugs in US adolescents: results of the National Comorbidity Survey-Adolescent Supplement. Arch Gen Psychiatry 69: 390-398.

Tirelli E, Laviola G, Adriani W (2003). Ontogenesis of behavioral sensitization and conditioned place preference induced by psychostimulants in laboratory rodents. Neurosci Biobehav Rev 27: $163-178$.

Tomasi D, Goldstein RZ, Telang F, Maloney T, Alia-Klein N, Caparelli EC et al (2007). Widespread disruption in brain activation patterns to a working memory task during cocaine abstinence. Brain Res 1171: 83-92.

Tseng K-Y, O'Donnell P (2007). Dopamine modulation of prefrontal cortical interneurons changes during adolescence. Cereb Cortex 17: 1235-1240.
Van den Heuvel DMA, Pasterkamp RJ (2008). Getting connected in the dopamine system. Prog Neurobiol 85: 75-93.

Van Swearingen AED, Walker QD, Kuhn CM (2013). Sex differences in novelty- and psychostimulant-induced behaviors of C57BL/6 mice. Psychopharmacology (Berl) 225: 707-718.

Verdejo-García A, Bechara A, Recknor EC, Pérez-García M (2006). Executive dysfunction in substance dependent individuals during drug use and abstinence: an examination of the behavioral, cognitive and emotional correlates of addiction. J Int Neuropsychol Soc 12: 405-415.

Williams RW, Bartheld von CS, Rosen GD (2003). Counting cells in sectioned material: a suite of techniques, tools, and tips. Curr Protoc Neurosci Chapter 1: Unit 1.11.

Winberg ML, Mitchell KJ, Goodman CS (1998). Genetic analysis of the mechanisms controlling target selection: complementary and combinatorial functions of netrins, semaphorins, and IgCAMs. Cell 93: 581-591.

Woicik PA, Urban C, Alia-Klein N, Henry A, Maloney T, Telang F et al (2011). A pattern of perseveration in cocaine addiction may reveal neurocognitive processes implicit in the Wisconsin Card Sorting Test. Neuropsychologia 49: 1660-1669.

Yetnikoff L, Almey A, Arvanitogiannis A, Flores C (2011). Abolition of the behavioral phenotype of adult netrin-1 receptor deficient mice by exposure to amphetamine during the juvenile period. Psychopharmacology (Berl) 217: 505-514.

Yetnikoff L, Eng C, Benning S, Flores C (2010). Netrin-1 receptor in the ventral tegmental area is required for sensitization to amphetamine. Eur J Neurosci 31: 1292-1302.

Yetnikoff L, Labelle-Dumais C, Flores C (2007). Regulation of netrin-1 receptors by amphetamine in the adult brain. Neuroscience 150: 764-773.

Yetnikoff L, Pokinko M, Arvanitogiannis A, Flores C (2013a). Adolescence: a time of transition for the phenotype of dcc heterozygous mice. Psychopharmacology (Berl) 231: 1705-1714.

Yetnikoff L, Reichard RA, Schwartz ZM, Parsely KP, Zahm DS (2013b). Protracted maturation of forebrain afferent connections of the ventral tegmental area in the rat. J Comp Neurol 522: 1031-1047. 